\title{
Regeneration of Atypical Ancient Villages Based on Phases of Proposal
}

\author{
Hui Chen, Xiyue Zheng \\ Faculty of Architecture, Hunan University, Changsha, China \\ Email address: \\ 331802521@qq.com (Hui Chen),362948152@qq.com (Xiyue Zheng)
}

\section{To cite this article:}

Hui Chen, Xiyue Zheng. Regeneration of Atypical Ancient Villages Based on Phases of Proposal. International Journal of Architecture, Arts and Applications. Vol. 4, No. 2, 2018, pp. 23-33. doi: 10.11648/j.ijaaa.20180402.13

Received: August 13, 2018; Accepted: September 13, 2018; Published: September 18, 2018

\begin{abstract}
With the list of traditional villages are constantly updated, more and more traditional village has attracted attention from society. But there are still a huge numbers of the Atypical Ancient Villages, which not on the "Traditional Village List", have not been well protected as they should be. It results in more and more depopulation and empty houses due to there are lack of enough protection and sufficient funds. Under those circumstances, the hollowization of these villages is becoming an increasingly serious problem. In fact, the empty village houses (including abandoned dwellings and empty architectural heritages) do not only waste land resources but also bring on many other problems such as safety hazard. Therefore, this article aims to takes HuanghuaPing Village as an example, to analyze the hollowing of Atypical Ancient Villages, and compares them with "empty house" problems in Japan. By learning from the research on Shodo-shima Horiuke area in Japan, we adopted the phases of proposal in HuanghuaPing Village design workshop, in order to explore a different activated solution for Atypical Ancient Villages. With the intervention of the new residents or visitors, and the structure network formed by the Aboriginal and the empty house as the main body, different activities will be implanted from the four stages of "spot problem" - "suggestion" - "implementation" - "feedback" to form a virtuous cycle to activate the village's vitality, and to regenerate the Atypical Ancient Villages.
\end{abstract}

Keywords: Architectural Heritage, Hollowization, Regeneration of Village, The Atypical Ancient Villages

\section{Introduction}

As a part of the world cultural heritage, the traditional village rooted in the local natural conditions and met the needs of production, had the characteristic of "small space, big society" They are a "living fossil" of different periods, regions, economic and social development stage. And they have the important value of scientific research. [1]By the end of 2014, Chinese traditional village has reached 2555. However, the protection of the traditional villages is determined by the "protection list ". In fact, there are still a large number of Atypical Ancient Villages which are difficult to be selected for the "traditional village list". These "Atypical Ancient Villages" which is between the traditional villages and the ordinary villages, are rarely concerned by the academia. By the end of November 2017, only 5 articles were related to the "Atypical Ancient Villages" in CNKI. Nevertheless, such villages are numerous and universal, forming the basement of the historical rural environment with
Chinese characteristics in the period of rapid urbanization, and they have high academic and practical value. [2] There are some problems in these villages, such as poor architectural heritage conservation and the lack of effective use of empty house from reasonable protection and development.

In addition, we have the opportunity to participate workshop "design intervention in rural activation" in 2017. In research, we found that HuanghuaPing Village is in conformity with the Atypical Ancient Villages, and there is a tendency of hollowing. Therefore, this article aims to explore ways to "activate" the empty house to protect and re-use the architectural heritage. The author takes HuanghuaPing Village as an example, analyzes the hollowing of Atypical Ancient Villages, and compares them with Japan's "empty house" problems. By using "phases of proposal" in HuanghuaPing Village design workshop, to explore a different activation method with the typical traditional village. 


\section{The Atypical Ancient Villages}

\subsection{Conceptual Analyses}

"Atypical Ancient village" is intermediate between the traditional villages and the ordinary villages, and is difficult to be selected for the "traditional village list" with abundant local characteristics and special location (Urban fringe). At present, the research methods of the Atypical Ancient Villages are compared with the traditional villages [2]. The Atypical Ancient Villages usually have the following characteristics:

First, they are not easy to be found from outside; Two, the cultural heritage is usually based on individual, thus faces the risk of disappear; Three, cultural relics are not as rich as the traditional villages, which can't meet the standard of the traditional villages. In addition, most of the historical buildings were randomly scattered in the middle of modern buildings. They don't have the features of historical buildings in traditional villages. Four, the "Atypical Ancient village" is facing the threat of being constantly eroded because it isn't in the "protection list" (lack of an effective policy for protection) [2].

However, "Atypical Ancient Villages" provide elastic space for development. In the historic relic, "Atypical Ancient Villages" usually retain a more complete landscape and street pattern, largely reflecting the idea of Chinese traditional residential environments. [2] And because it isn't subject to the relevant regulations, so it can have more free space to play a role in the process of architecture protection. [3]

\subsection{HuanghuaPing Village, Shaxi Town, Dali City, Yunnan}

\subsubsection{The Basic Condition of HuanghuaPing Village}

HuanghuaPing Village belongs to Shaxi town in Lijiang city, Yunnan Province, which is a typical Bai village and located in the dam, about one kilometer distance from Temple Street. The location of the village is far from the main road (Figure1). New houses are is pushing northward. The main road runs east-west. Most buildings are concentrated on the south side of the road. The north-south road extending from the village square is the earliest development axis of the village. Although the village has a certain geographical advantage in Shaxi, but the gate of the village is too narrow to on exposure.

There are 386 people, 83 households, and all the people are the Bai in HuanghuaPing Village. In 2014, the gross production value of HuanghuaPing village was 1 million 685 thousand yuan, and the farmers' income was dominated by livestock production and animal husbandry.

\subsubsection{The Main Characteristic of the HuanghuaPing Village}

The building envelopes of Bai houses mainly adopted mud (part of them used loam wall). HuanghuaPing village which relying on Shaxi, where had an unimpeded view of the village (Figure2).

The traditional culture is divided into two types: cultural relics and intangible culture. On the one hand, traditional wood carving and Bai houses with distinctive characteristic are gradually dying out; on the other hand, intangible culture is threatened with disappearance, only few traditional festivals remain such as Torch Festival.

Based on the status of HuanghuaPing Village: special geographic position (Urban fringe) ; Not easy to be found outside; the intangible cultural heritage such as wood carving, embroidery in the face of disappear; only 6 historical buildings, which can't meet the standard of the traditional villages; 6 historical buildings were scattered, what doesn't conform to traditional villages (concentrated distribution). By this reckoning, HuanghuaPing Village belongs to type of Atypical Ancient Villages.

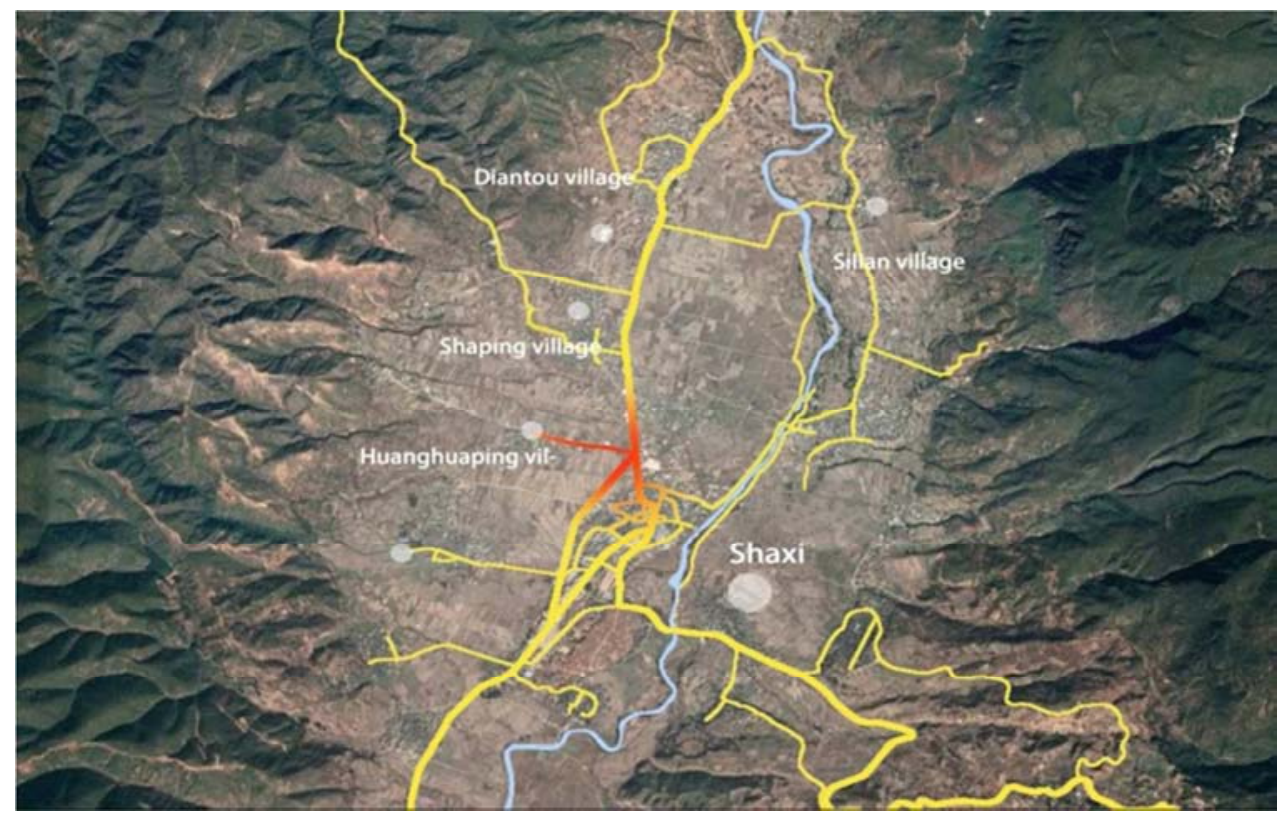

Figure 1. Site of HuanghuaPing village. 


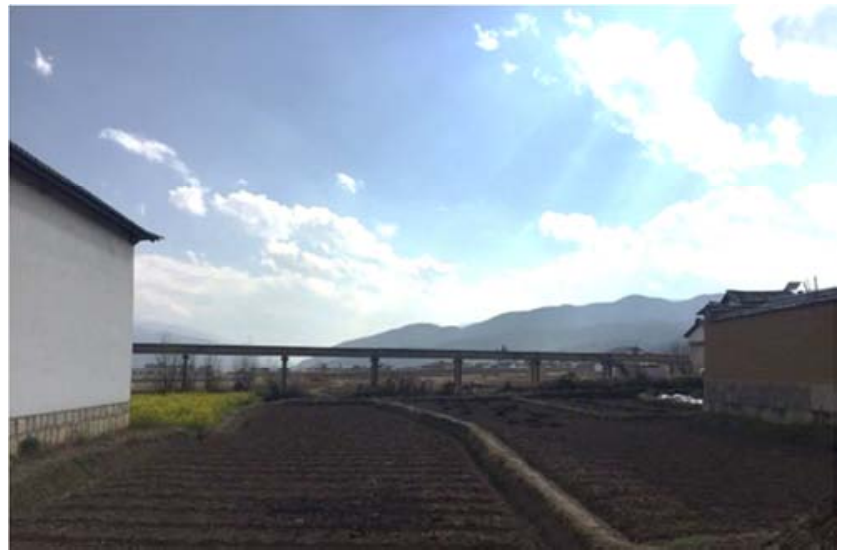

Figure 2. Landscape of HuanghuaPing village.

\section{The Hollowing Trend of Atypical Ancient Village}

\subsection{Definitions, Manifestation, Harm and Formation Mechanism of Hollowing}

The hollowing in village is the process of exploding outward and hollowization. The definition of hollowing is divided into three: First, from the aspects of population change, including population and population structure change to explain the phenomenon; second, from the change of the village spatial pattern; third, from the aspect of economic and social phenomenon, population outflows caused bad results such as degradation of economic. [4]

The hollowing of Atypical Ancient village is mainly manifested in "material hollow" population, industry, building and "cultural hollow" for what traditional activities have not been formed in modern community culture. [5] At the same time, the hollowing in Atypical Ancient village not only caused consequence with wasteful resource in culture and architecture. It also makes mutual problems in ordinary villages. For instance, agricultural production faces challenges, endowment problem and unattended children and the living environment of villages are difficult to improve. [6] As a result, architectural heritage and traditional culture can't be effectively protected.

In order to suppress the trend of hollowing in the Atypical Ancient village, it is necessary to analyze the formation. The reasons are mainly four aspects: economic, political, legal and comprehensive. From comprehensive, the reasons are the core driving force and the external pull power. (Table. 1)

Table 1. Formation mechanism of hollowing.

The development of the village is an ill fit with the increasing demand of the villagers.
For example, basic facilities, educational resources, medical resources, and so on
The protection and management of the village's architectural heritage are not in place.
Although there is Law on the Protection of Cultural Relics and local regulations, most of the houses are not listed as heritage unit,
so they are not to be protected. And basically building property right belongs to the private, so the government's involvement is
difficult. At the legal level, Atypical Ancient Villages do not get effective legislative protection [1]
The lack of awareness of heritage conservation and the sense of home identity (for villagers)
On the one hand, due to the lack of effective guidance and education of the villagers, most of the villagers did not understand the
significance of heritage, but see heritage as an effective economic means, which could not be established the sense of home
identity; on the other hand, deplorable dwelling environment made villagers attempt to torn down historic buildings for improve
the living environment. Or, historic buildings were abandoned
Villagers are attracted to surround towns. Cities often have higher incomes and better conditions.

\subsection{The Manifestations, Causes and Consequences of the Hollowing in HuanghuaPing Village}

The hollowing of HuanghuaPing village is mainly shown in the following two aspects: First, the hollowing of population. There are many old and women left in the village. On the basis of my own observations, almost all the farmers in the field are women and old people (Figure3), and the young men are rarely seen. Two, the hollowing of houses. Depopulation directly affects the hollowing of the houses (Figure4). Many people are building new houses along the road. And, 6 historical buildings, having been bought by the government, were not used to the full.

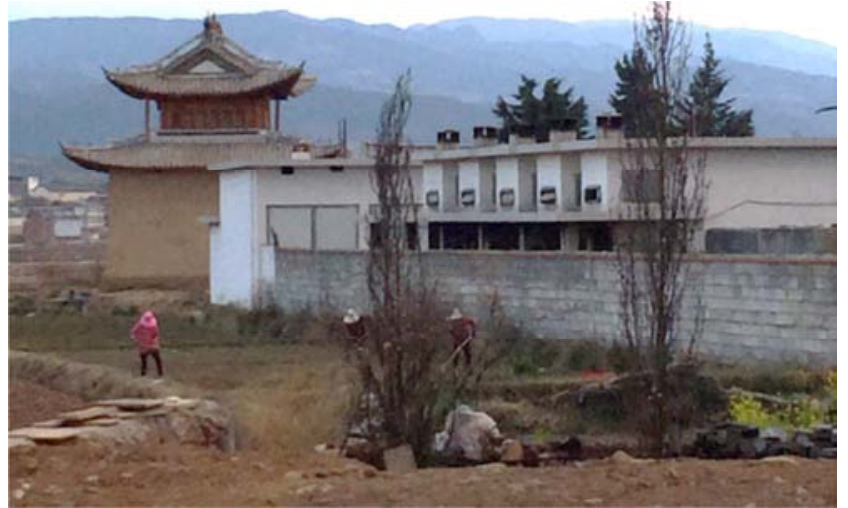

Figure 3. Women and old people working in the fields. 


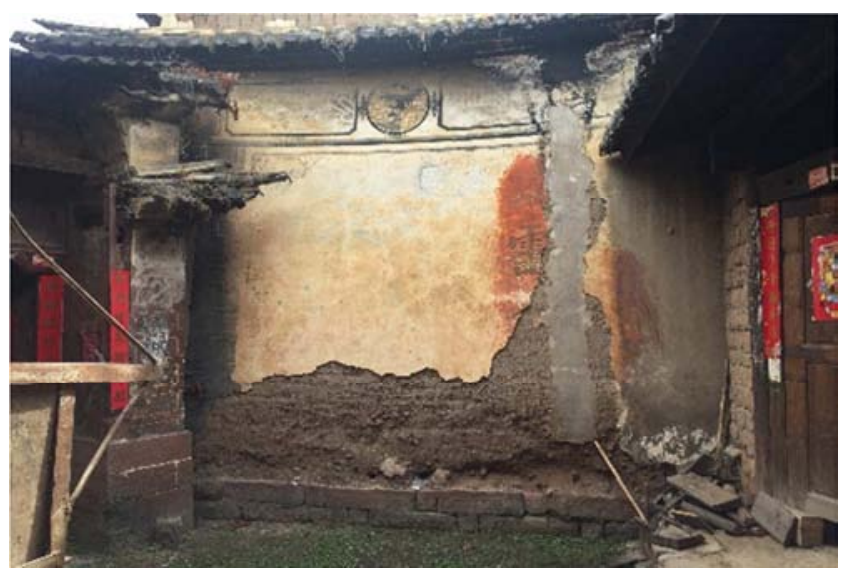

Figure 4. Historical buildings.

Reasons for the hollowing of HuanghuaPing village are summarized as follows: First, the core driving force. The development of the village is an ill fit with the increasing demand of the villagers; The protection and management of the village's architectural heritage are not in place; Lack of public space and so on. Second, external pull power. The lack of gravity of the surrounding towns and supporting industries in HuanghuaPing village can lead to depopulation (most young people are working in other parts of the country).

Moreover, with the loss of the main body of protection (villagers) in HuanghuaPing village, the intangible cultural heritage in the face of disappear; And, the hollowing of the building also causes worsening environment, which brings a detrimental effect on public safety and public hygiene.

\subsection{THINKING of Solving the Problem of the Hollowing in Atypical Ancient Village}

The trend of hollowing is an important element of the inactivation of traditional villages. The ultimate aim of Rural Revitalization is to solve problems that including the hollowing, so Rural Revitalization resemble hollowing problem solving strategy which discussed in this paper. But generally speaking. Most activation in traditional villages is usually guided by tourism [7], making value judgments about villages, and analyzing their advantages and disadvantagesdeveloping the tourism industry with the heritage. Through the "solid" of the building to realize the "solid" of the population. There are also many ways in activating the common villages, such as the establishment of new rural communities, the migration of different villages, and the combination of villages [8]

However, Atypical Ancient Villages are not suitable for unfavorable and blind development of tourism. These reasons are as follows: First, poor communications and it are not easy to be found. Two, most of the village's material heritage are seriously damaged, and the intangible cultural heritages are mostly lost. So they were ineligible for developing the tourist industry. Three, the hollowing will lead to a lack of labor, so the foundation of tourism is not strong; Four, there is little government or business support (lack of sufficient cultural characteristics and environmental appeal.) Meanwhile, comparing with the ordinary villages, there is material heritage in the Atypical Ancient Villages. Building new rural communities and migrating to other villages that will lead to the lack of characteristics of the village.

$\mathrm{Xu}$ Pengfei believes that the main cause of the hollowing of village is not the departure of people, but the lack of public activities. Sun Junmin spoke about the fundamental reason for hollowing is lax village collective (In Xinyang City, Henan Province). [9] Therefore, for the activation of a region, the first thing is the activation of the human. Only by activating people's mind, increasing public activities, keeping traditional memories and establishing a sense of hometown identity, can we introduce tourism and development industry to activate villages. [10]

Therefore, we are in urgent need of a new method from inside to outside.

\section{Enlightenments from the Case of "Empty House" in Japan}

\section{1. "Empty House" and Reuse of "Empty House" in Japan}

\subsubsection{The Definition of "Empty House" and the "Empty House” Problem}

Japan is on the background of a few children and aging. According to a survey in 2013, the total number of empty houses in Japan has reached 60.63 million, and they are up $5.3 \%$ in 2008. 'Uninhabited houses known as "empty house", refers to no residential or other purposes (becoming normal), empty home also including the proportion of the land (except for national or local public entities owned or managed.). Empty houses are caused by various reasons, such as depopulation and the increase of apartments and, so on. [11]

\subsubsection{Advancing the Use of "Empty House" System and Types of Use of "Empty House"}

At present, there are empty house bank and special measures for empty houses to advance the use of "empty house" in Japan.

Bank system, refers to "a kind of mechanism to collect information about empty houses for sale in local public entities on the network, this system can connect with which hoping to move to the place.

On November 19 in 2014, in order to protect people's lives and property, Japan's Ministry of land and Infrastructure and Transport announced the action of special measures for empty houses.

The four types of use of "empty house" are follows: residence, resource, commercial and preservation.

\subsubsection{The Case of "Empty House" in Japan Is an Object Lesson}

Because both China and Japan are influenced by the traditional Confucian culture and small-scale peasant economy, they have similar internal and objective laws.

\footnotetext{
${ }^{1}$ The Studio-nasca. A regional reserve report about Shodo-shima.2014
} 
Japan's administrative system is similar to that of China. Japan has also experienced the problems of rural land waste and population outflow. [12]It is facing the decline of rural communities, the aging of the agricultural population, the over-thinning and problem of empty houses. [13]

By comparing Table 2, we can see there are similar features, such as the phenomenon and the consequences (no use of empty houses, which caused health and safety issues and so on; uninhabited lead to waste of resources). In addition, there are many similarities in the research on its objects, such as activation, village renewal, reuse of the building, etc.

Therefore, we think there is a possibility to learn lessons from Japanese experience.

Table 2. The Atypical Ancient Villages in China and villages in Japan.

\begin{tabular}{lll}
\hline & The Atypical Ancient Villages & Villages in japan \\
\hline \multirow{2}{*}{ Subject } & Traditional houses (bought by the government) & The empty house and its land \\
& Empty house (only house-ownership) & house-ownership and land-ownership \\
Phenomenon & The vacancy of the architectural heritage & Safety problems \\
& The old house is constantly ruined & Public health problem \\
Reason & The government did not use & Reduction of children \\
& Moving out of the population & An increase of apartments \\
Property right & Government & Individual ownership \\
& Individual ownership & depopulation \\
\multirow{2}{*}{ Correlation studies } & Rollowing & Regional activation \\
& Village renovation & village renovation \\
& The protection and & The restoration and reuse of empty house \\
\hline
\end{tabular}

\subsection{Shodo-Shima Horiuke Area as the Use of "Empty House" Case Study}

\subsubsection{Research Status of Shodo-Shima Horiuke Area}

Shodo-shima is among the Shikoku, Honshuu, and SetoNaikai. And it is still the second island in Japan. (Figure 5-6).

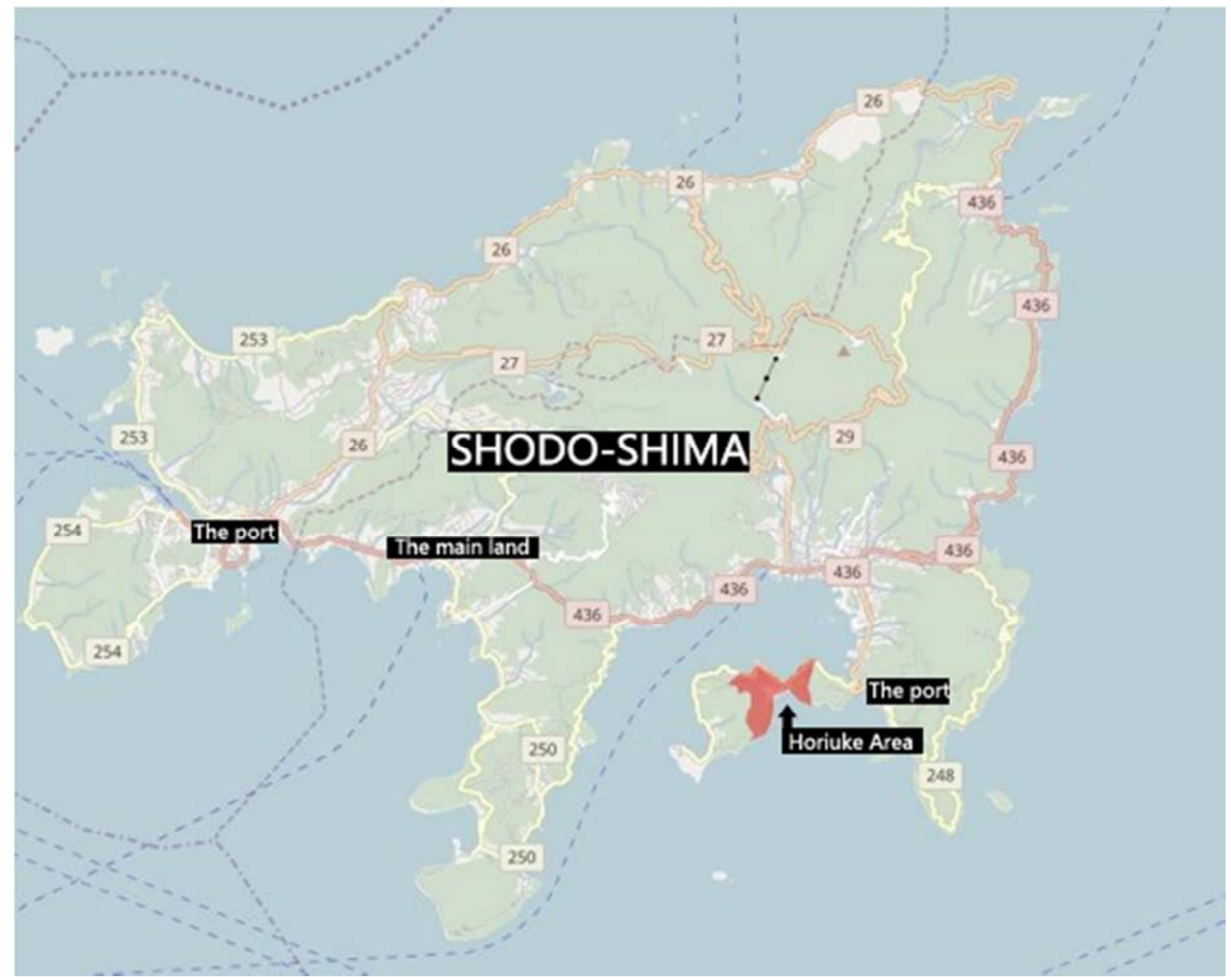

Figure 5. The site of Shodo-shima. 


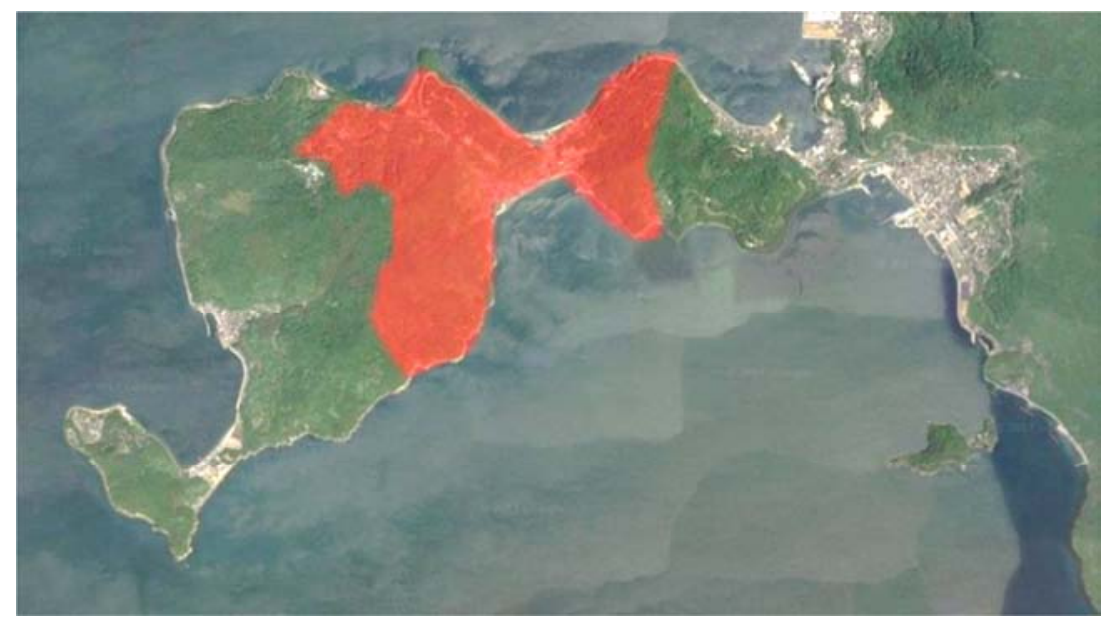

Figure 6. Satellite image.

According to the Studio-nasca (2013), Shodo-shima's population is about 91 , and it has 45 households. The aging rate of Shodo-shima is as high as $51 \%$. Compared with the population aging, more serious problem is that empty houses reached 22. In addition, the increase in the number of people in 11 prefectures in Japan than in the previous year, according to the population survey conducted by the prefecture (one of them is Shodo-shima). Meanwhile, in order to promote the immigration policy, Shodo-shima adopted the empty house bank system to collect information and introduced them on the home page of the empty house bank. [14] Therefore, the Studio-nasca chose this place to study the village renewal with migrants and the reuse of the empty houses.

\subsubsection{Proposal by Phase}

In a previous survey, the Studio-nasca investigated the position, structure and aging ratio of houses what registered in the empty house bank. Based on the results of the survey, $h$ area (The highest number of emigrants) and $n$ area (The highest percentage of emigration) were selected in the empty house bank. And in $\mathrm{h}$ and $\mathrm{n}$ areas, the Studio-nasca did surveys such as questionnaire, interview, an empty house survey, working line survey and residential plan sketch. Thus, it is concluded that two factors (the migrants and the empty house) are essential to the activation of the region. [14]

Proposal by phase denoted that a network organized by migrants, native people and empty houses; From four steps including Spot problems, suggestion, implement, feedback. Through continuous discussions with the government and the residents, different activities are implanted at various stages to promote the activation of the whole region.

(1) Spot problems

The Shodo-shima area has the following problems at present: First, because the lights are scarce, the town entered the dark at night. Two, the abandoned Koujinnja are not in reasonable use. Three, there is no place for residents to rest. Four, the flow of information is not as quickly as city in this place, so it will make people's interests becomes relatively narrow. Five, there is a lack of direct communication between people and people (especially migrants and native people). It puts forward some proposals to solve these problems, and it also let native people try to find enchantments from a different way.

(2) Suggestions

By sorting out problems and enchantment, they got some proposals to solve problems. Setting the table in the Binhai Road, and placing candle on these tables, the candle is so bright that it deflects darkness; Converting the deserted Koujinnja into theatre; Space is provided for people to communicate with each other, they would like to set more chairs in that place where is relaxing; An information island will be a place that people could collect information and share all kinds of interests; Building a view platform for communication.

(3) Implementation and feedback

On August 16, in 2014, Nouryou festive which was called "beer garden" had held "candlelight dinner" and "starlight". The Studio-nasca also conveyed information to all parts of the world through the 2016 Seto Arts Festival, and planned to use empty houses in a different way for migrants, native people, visitors and children.

\subsection{Summary}

The Studio-nasca was investigating the use of empty houses with migrants for regional update. And the static role of the empty house is indispensable to the dynamic role of the migrants on their own. The new perspective of the migrants enables the native people to have the opportunity to reconsider and discover the enchantments of which place they live in. Migrants who moved into this region will help the region to update. Empty house like this will be the basis for migrants to attract talents and help them integrate into the new region. The role of the empty house is not only for housing, but also for migrants to integrate into the region. Meanwhile, the repaired empty house can also become a local landscape. [14] 


\section{Attempt to Solve the Problem of Hollowing in HuanghuaPing Village by "Proposal by Phase"}

\subsection{Proposal by Phase in HuanghuaPing Village (Figure 7)}
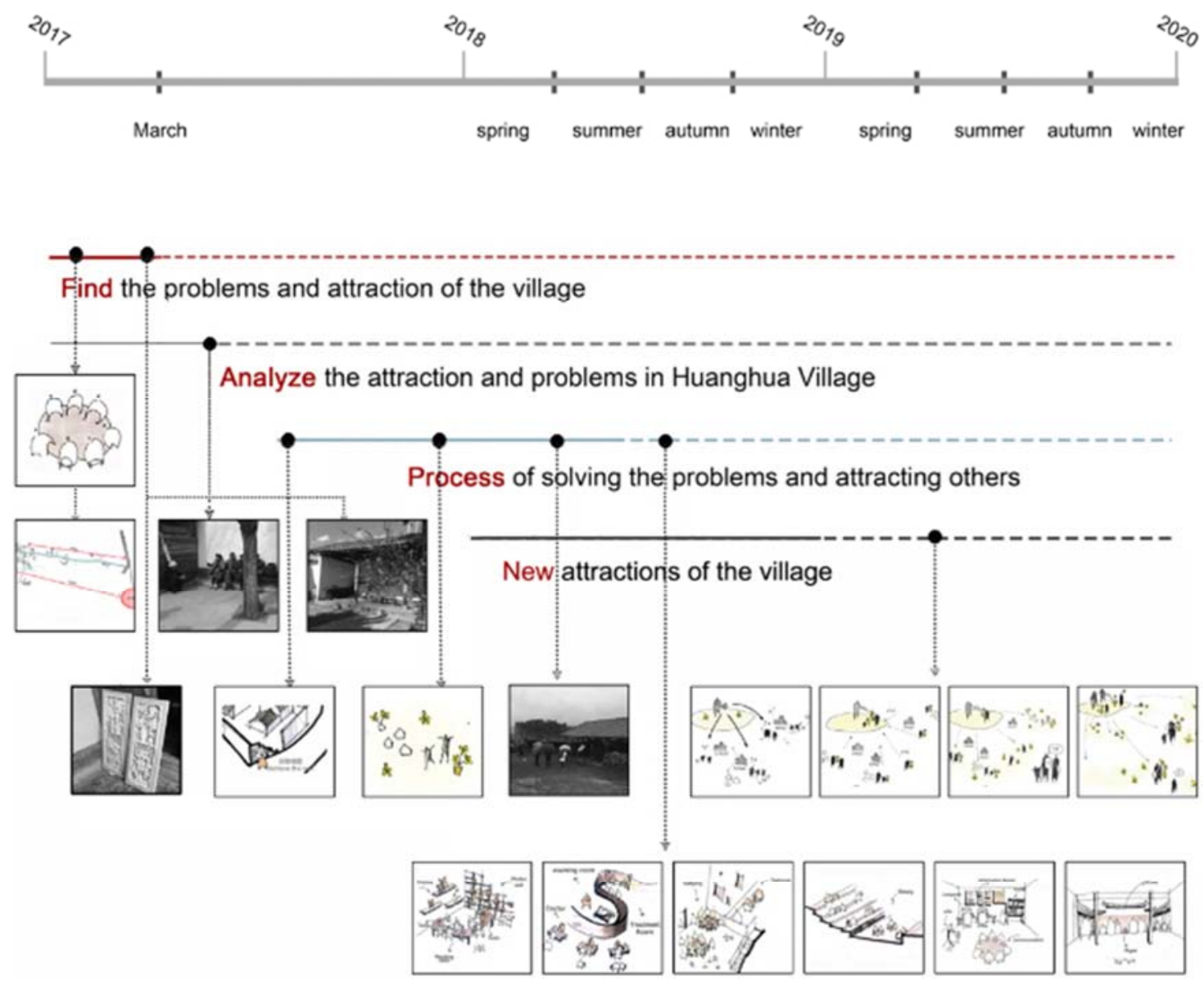

Figure 7. Proposal by phase in HuanghuaPing Village.

\subsection{Thinking of Activation}

\subsubsection{Spot Problems}

(1) Entrance road. The dust-covered road to the village is no trees to cover up, and is lack of marking. And HuanghuaPing Village Ping is not directly related to surrounding villages. So visitors cannot know the specific location of HuanghuaPing village. (Figure8)

(2) Public space. There is only one small square in the village (Figure9), which is often used for parking lots. As a local community, the utilization rate of public buildings is low, and more people are willing to squeeze under the willow (Figure10).

(3) Inheriting and developing the tradition of Chinese culture. The traditional wood carving and Bai culture are gradually dying out, but few people are willing to learn about them.

(4) 6 historic buildings have been out of use. Many houses are abandoned.

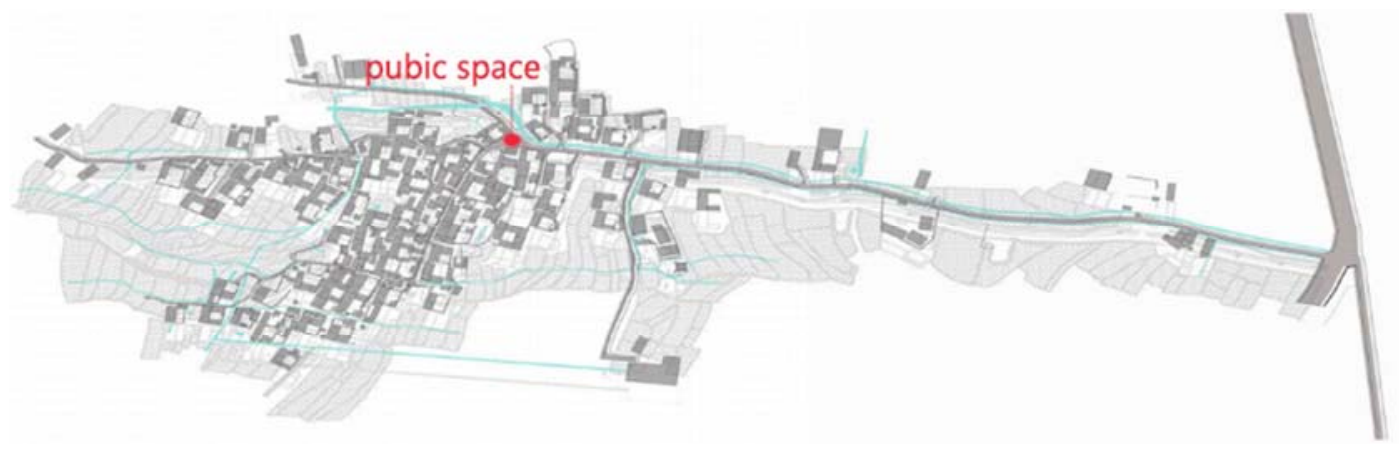

Figure 8. Entrance road. 


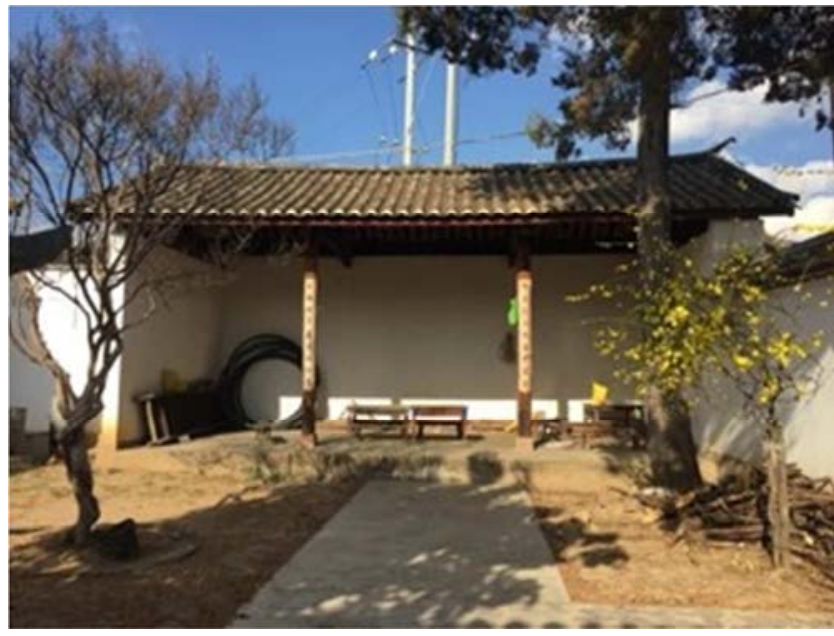

Figure 9. Public space at present.

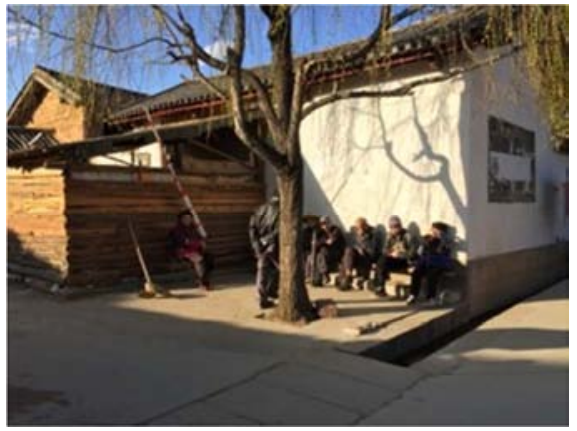

Figure 10. People are under the willow.

\subsubsection{Recommendations and Implementation}

The Figure (Figure11) suggests that there are such problems: the public space in the village are too small at present, people have turned the entry of the local community into a parking area, the walls of empty houses block the sight in the open area. It is to be observed that the Zhai Men which was originally the symbol of the HuanghuaPing Village had disappeared. Based on the current situation of HuanghuaPing village, here are ways to activate it:

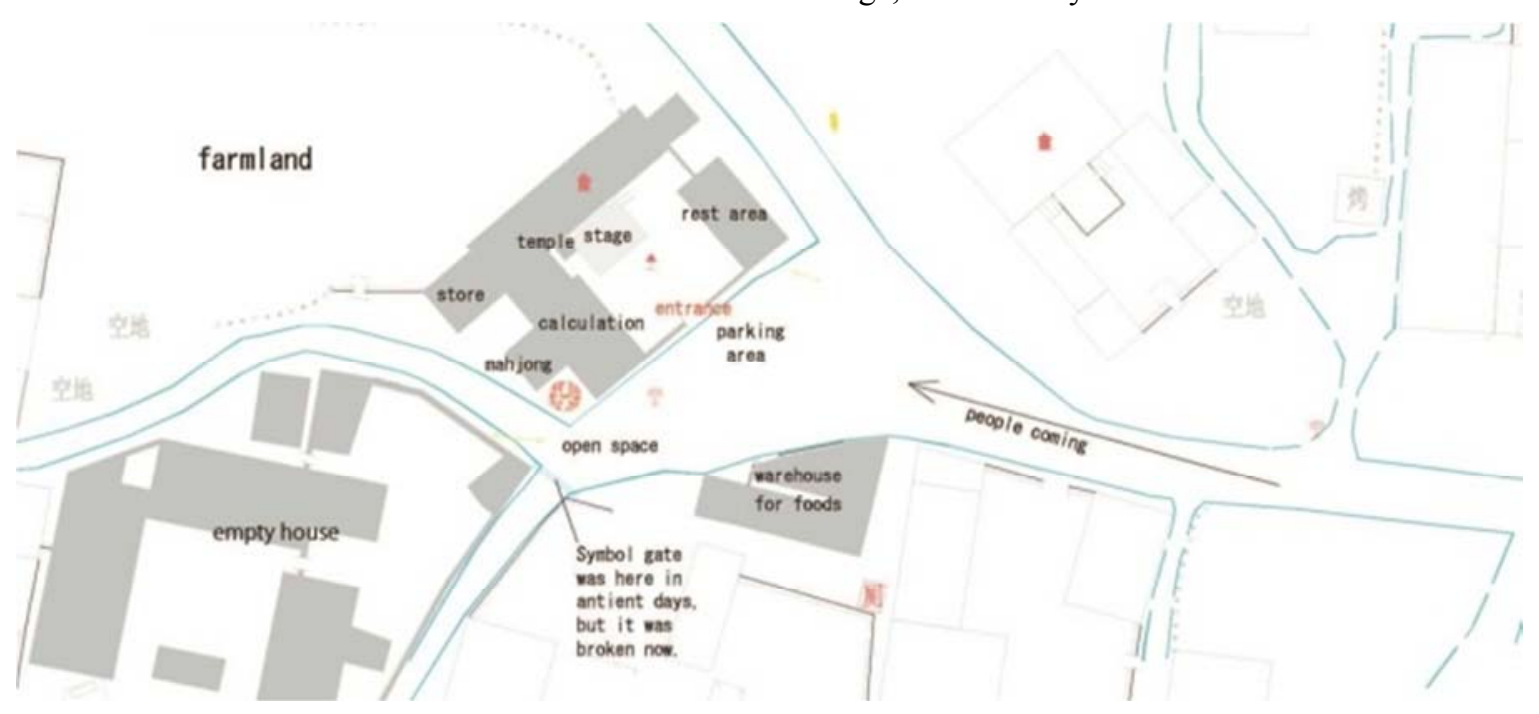

Figure 11. Present situation.

First of all, we could investigate the situation of the historic building and draft drawings. At the same time, putting forward the solution and cleaning according to the results of the discussion. Then, removing the wall of the historic building, and making it into a public space. After transferring the existing parking area (transforming the parking space into public space), allowing public space connects with the surrounding space. Reconstruction of mahjong room parallel to the direction of old Zhai Men, to build a new entrance axis. Then, turning local community into the rest room for people who repaired historic building or cleaned the road. By workshop of tile factory, the tile factory will become a new node on the road which will lead to the village. It also can provide visitors a chance to learn and experience the production process of tile products. Some suggestions for adding more functions in historic building, such as a library, workshop of wood carving. When the road planting has been completed, the original Temple space is becoming a bicycle parking area, which is conducive to the arrival of outsiders. At this point, historic building where is provided for people to communicate with each other has more features, such as public kitchen, exhibition space. (Figure12)

\subsubsection{The Feedback and Future}

We could revise the plan for the modification of empty houses by feedback. At the same time, we hope that in the future the traditional culture of HuanghuaPing Village will take root and spread like a seed around children. In school (there are 5 schools around HuanghuaPing Village); the traditional culture of Huang Hua Ping is spread to a larger scale. 


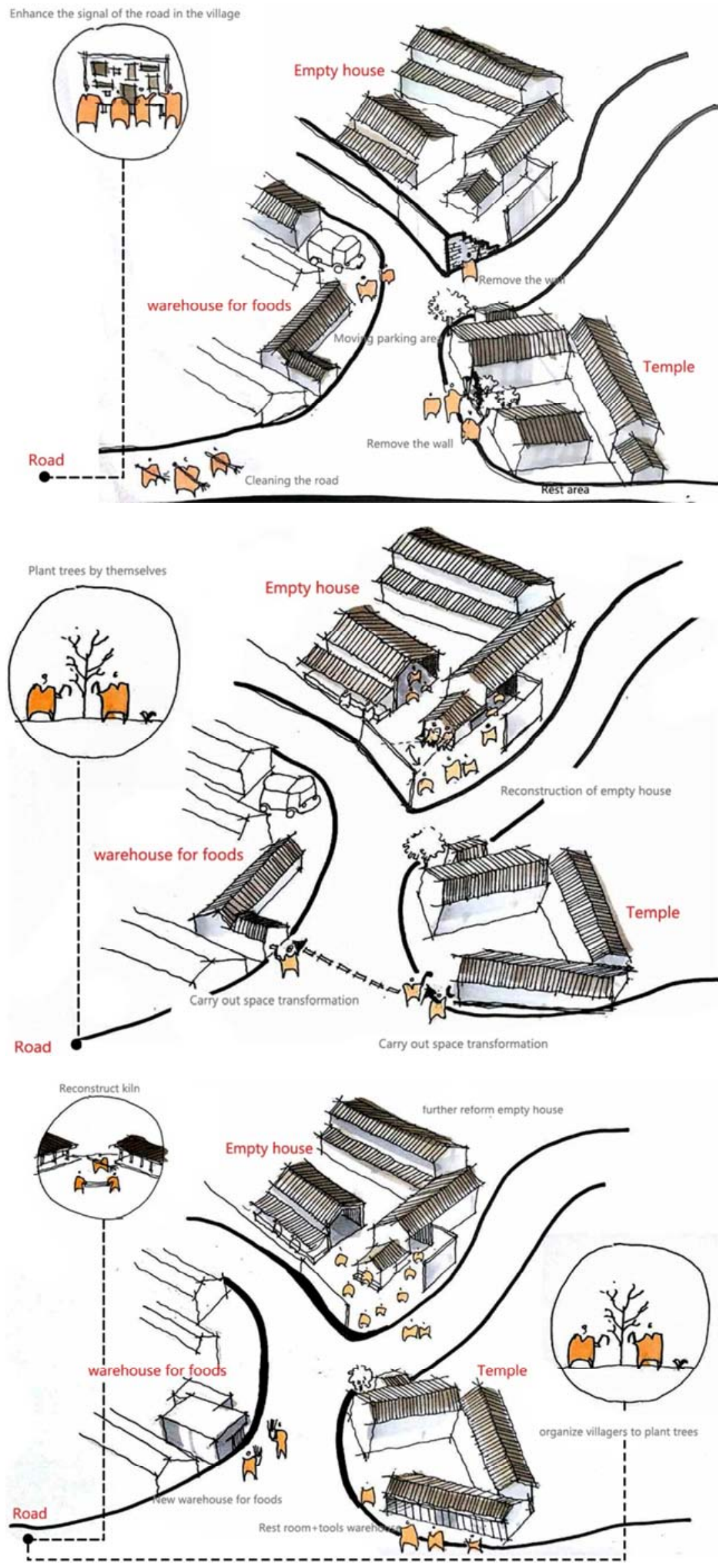




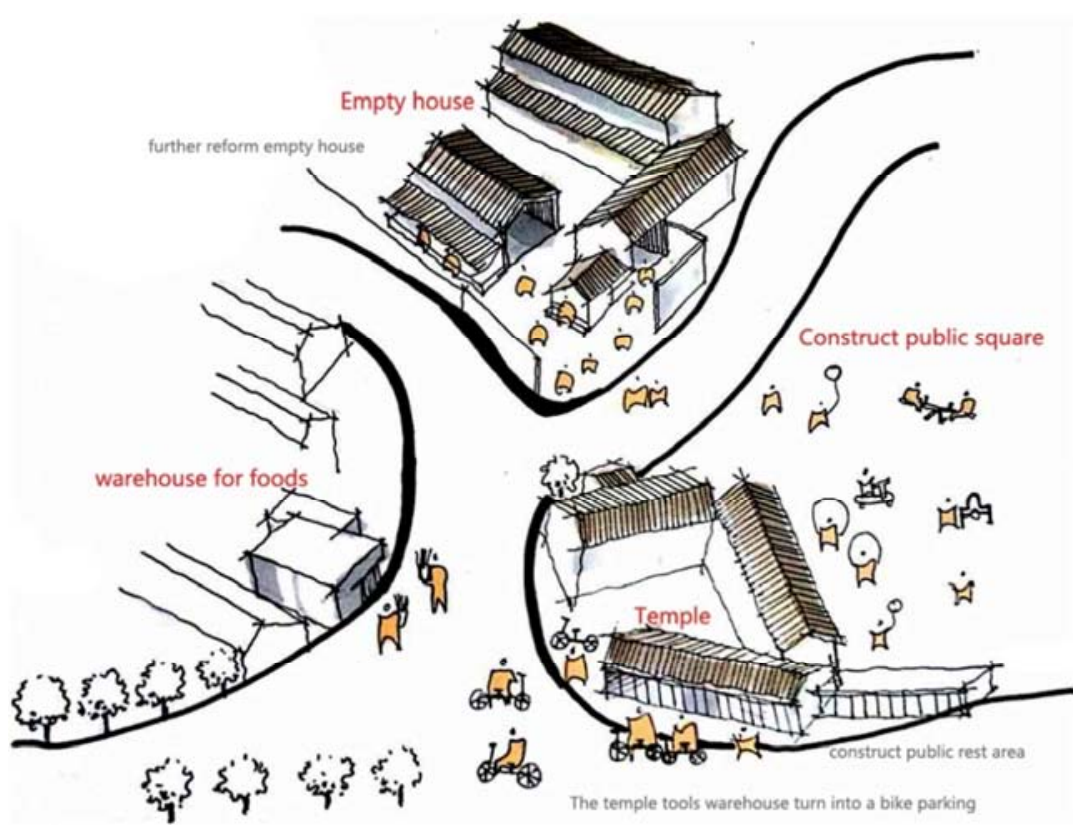

Figure 12. Implement procedure.

\subsection{Summary}

Under this background of return of the country gentleman, advocate the artist to the countryside, master plan, and young volunteers. Their role is similar to Shodo-shima "migrants" who could contact with the outside world, provide a different perspective for HuanghuaPing village, and find enrichment of village with native people. From four steps including Spot problems, suggestion, implement, feedback. Through continuous discussions with the government and the residents, different activities are implanted at various stages to promote the activation of the whole region. The empty house in Shodo-shima as the historic building which was purchased by the government or a discarded ordinary house as in the Atypical Ancient village. 6 historic buildings can be used as the leisure center, library or other public space. The abandoned house can also be used for residence through repairing, and become the foundation for new residents or visitors to integrate into HuanghuaPing Village. Meanwhile, they will become a new landscape of HuanghuaPing Village. [15]

\section{Conclusion}

For the Atypical Ancient Villages, the hollowing has become a great obstacle to its development. And, the study of the over - thinning in Japan started earlier, and there is reasonable literatures focus on the empty house and the reuse of empty house. And there are similarities between the empty house and the architectural hollowing in the Atypical Ancient Villages. So we could learn lessons from Japanese experiences.

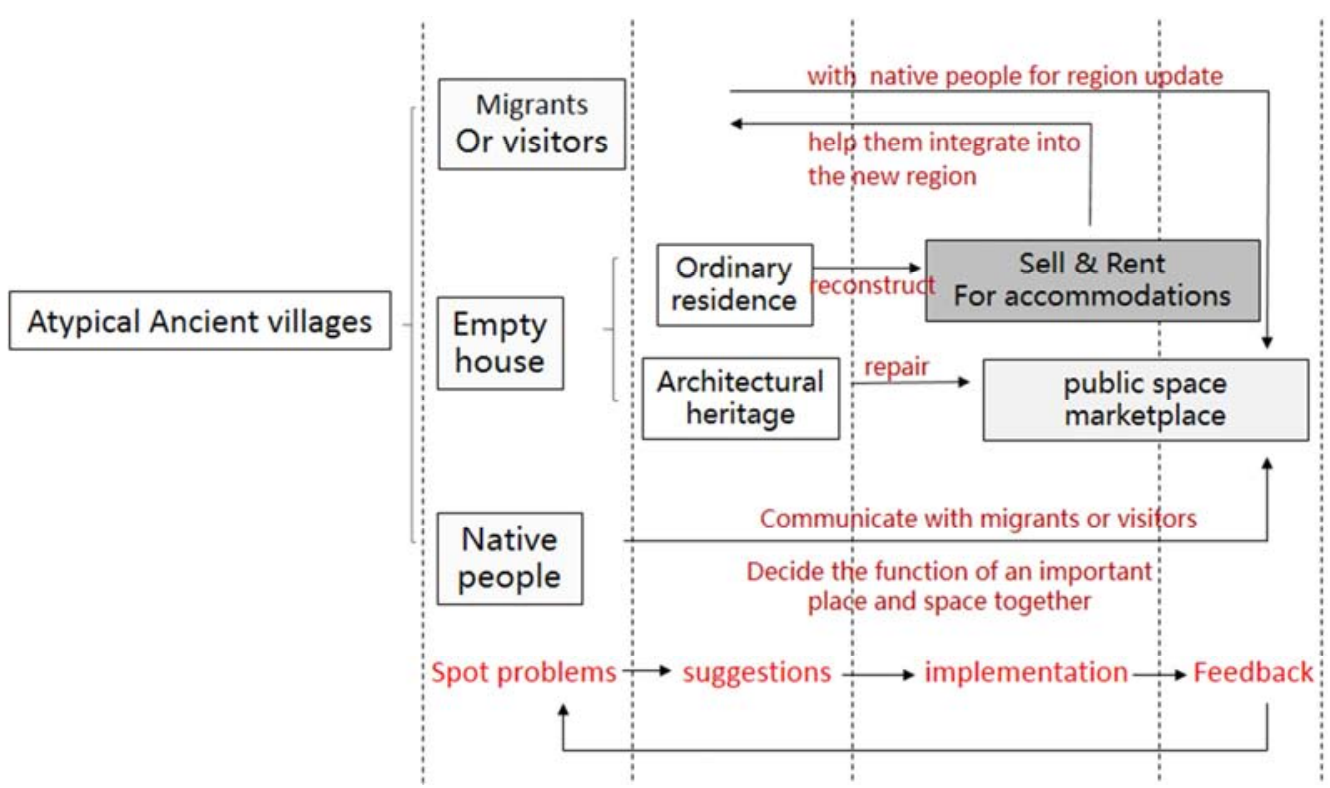

Figure 13. Active network. 
Lack of policy support and funds, "Proposal by phase" is based on the characteristics of Atypical Ancient Villages with new residents or visitors can be more feasible (Figure13). We can use architectural heritage as public space to activate region. The idea is to guide villagers to change their idea, reconstruct public life. So it could hang on people, attract people to come back.

This paper is only based on the thinking of the workshop of HuanghuaPing Village, in order to provide reference for the treatment of the hollowing of the Atypical Ancient Villages in China.

Footnote: Figure7-12 are selected from the "Growth" of the first prize program in the HuanghuaPing Village design workshop in 2017.

\section{References}

[1] Wei Cheng. Where the Way is: Dilemma and Outlet of Uninhabited Ancient Village's Protection [J]. South Architecture, 2009 (4): 21-24.

[2] Wu Xiaoqing, Jingxiang Zhang, Wu Zhengdong. Discussion of the Plight and the Countermeasure of Protection and Renaissance of "the Atypical Ancient village "Locate in the Edge of the City: A Case Study of Doucun [J]. Modern Urban Research, 2015(05): 99-106.

[3] Kong Weijie, He Yi. Selective Conservation of the Heritage in "Atypical Historic Villages": A Case Study of Xiashui Village In Dongqian Lake, Ningbo [J]. City Planning Review, 2018 (1): 101-106.

[4] Huang Kaiteng. Research on Rural Hollowing Management: A Review Perspective [J]. Agricultural Economy, 2018(1): 4749.

[5] LIN Zurui, LI Nannan, CHANG Jiang, TIAN Mengsi. The Differentiation Characteristics and Formation Mechanism of Hollowrization in Traditional Villages: A Case Study of the Traditional Villages in Yangquan, Shanxi [J]. Modern Urban Research, 2016(1):16-23.
[6] Wang Chengxin, Yao Shimou, Chen Caihong. Empirical Study on "Village-Hollowing" in China [J]. Scientia Geographica Sinica, 2005 (3):3257-3262.

[7] Shi shaohua, liang jialui. Traditional villages and tourism: nostalgia retention and activation $[\mathrm{J}]$. Changbai journal, 2018(4)

[8] Li Zengyuan, Li Hongqiang. Rural Community Governance: Current Situation, Problems and Countermeasures [J]. Zhongzhou Academic Journal, 2016, No. 232 (4):66-72.

[9] Xu Pengfei. Paying attention to the traditional villages is the key to solve the hollowing [J]. People's Daily. Rural Science and Technology, 2017(11): 7-7.

[10] Jiang xinyue, wu zhihong. Enlightenment on Community Creation to Activation of Rural Areas in China: A Case Study of Village Activation in Shimane-Ken [J]. Urban construction, 2018(11).

[11] Ihara Mitsuaki. Eco-tourism and Eco-museum: Japanese Experiences [J]. Development of Small Cities \& Towns, 2018(4).

[12] Wang lei, $\mathrm{Zu}$ yunqi. The Decline Phenomenon of the Depopulation of Japan's Small Towns and Its Countermeasures [J]. Huazhong Architecture, 2016(11): 96100.

[13] Zhang Li. Similarities and Disparities: Learning from East Asian Rural Development and Planning: Interview with Li Jingsheng, Professor of CAUP Tongji University [J]. Urban Planning International, 2016, 31(6):49-51.

[14] Nanami Tetsukawa, Tomoki Nemoto, Atsuya Inagaki, etc. 6106 Laboratory for coexistence with the inmates and renewal of village Research: A case study of Shodoshima-cho vacant house bank system (empty house activities, rural planning, built in 2014 Architectural conference meeting (Kinki) academic lecture / architectural design presentation) [J]. Academic lecture collection, 2014: 217-218.

[15] HE Yong, SUN Wei, MA Ling-yan. Rural Construction as a Concept and Method [J]. Architectural Journal, 2011(4):1922. 